\title{
ÁREAS CONSOLIDADAS EM ÁREAS DE PRESERVAÇÃo PERMANENTE E SUA CONSEQUÊNCIA À PROTEÇÃO AMBIENTAL
}

Cláudio José Donato ${ }^{1}$, Irene Caires da Silva ${ }^{1}$, José Luís de Lima Astolphi ${ }^{1}$, Joselene Lopes Alvim ${ }^{1}$, Maira Rodrigues Uliana ${ }^{1}$, Taís Muller ${ }^{2}$

${ }^{1}$ Universidade do Oeste Paulista - UNOESTE, Presidente Prudente, SP. E-mail: claudio.donato@hotmail.com

${ }^{2}$ Universidade Estadual de Maringá - UEL, Campus de Umuarama, Umuarama, PR.

\section{RESUMO}

A Constituição Federal, no art. 225 elevou ao patamar dos direitos fundamentais a proteção ambiental, instituindo inúmeras medidas e tutelas jurídicas a serem implementadas, dentre elas, exigiu a criação de espaços territoriais de proteção ambiental. É nessa modalidade que se inserem as Áreas de Preservação Permanente - APPs. Sendo assim, o presente estudo busca analisar os benefícios e malefícios dos espaços consolidados em Áreas de Preservação Permanente para garantir a proteção ambiental e conciliar com o desenvolvimento sustentável. A realização desta investigação científica será elaborada a partir de uma pesquisa bibliográfica, que buscou o levantamento de informações para obter o conhecimento existente sobre o tema. Após a averiguação, conclui-se que a gestão ambiental de Áreas de Preservação Permanente proporciona a oportunidade da integração dos esforços para a conservação da floresta e da água, buscando a melhoria da qualidade de vida das populações residentes e a gestão de conflitos no uso dos recursos naturais.

Palavras-Chave: Preservação Ambiental, Proteção Ambiental, Áreas de Preservação Permanente, Gestão Ambiental, Desenvolvimento Sustentável.

\section{CONSOLIDATED AREAS IN AREAS OF PERMANENT PRESERVATION AND THEIR CONSEQUENCES TO ENVIRONMENTAL PROTECTION}

\begin{abstract}
The Federal Constitution, art. 225 raised the level of fundamental rights protection, instituting numerous environmental and legal guardianship measures to be implemented, among them, demanded the creation of territorial spaces of environmental protection. It is in this mode are the Permanent preservation areas-APPs. Thus, the present study seeks to analyse the benefits and harms of consolidated spaces in Permanent preservation areas to ensure environmental protection and reconcile with sustainable development. The realization of this scientific research will be drawn from a literature search, which sought information about lifting the existing knowledge on the subject. After investigation, it is concluded that the environmental management of Permanent preservation areas provides the opportunity of integration of efforts for the conservation of the forest and water, aiming at improving the quality of life of the populations residents and the management of conflicts in use of natural resources.
\end{abstract}

Keywords: Environmental Preservation, Environmental Protection, Areas of Permanent Preservation, Environmental Management, Sustainable Development.

\section{INTRODUÇÃO}

O meio ambiente por um longo tempo foi considerado como uma fonte inesgotável de recursos, atuando na produção de matéria-prima capaz de promover o desenvolvimento 
econômico acelerado das nações, sem ter a consciência de que o uso inadequado dos recursos naturais causa danos irreversíveis e perda da vida de todos os tipos. Neste sentido, ressalta-se que o uso exagerado de recursos ambientais, sem escrúpulos, que no Século XXI deflagrou consequências negativas para a sociedade, que se demonstrou despreparada para lidar com questões de grande complexidade. Tal situação tem levado à busca de soluções para a problemática ambiental.

Neste compasso, as questões ambientais nos últimos anos têm sido amplamente debatidas em vários campos do conhecimento, uma vez que a sociedade foi impulsionada a buscar soluções diante dos efeitos deletérios causados pelo avanço da degradação do meio ambiente. Uma forma de combater a destruição da natureza é a conscientização da sociedade em relação a este assunto, buscando soluções para deter a devastação (BORGES, 2011).

A emergência dos problemas ambientais trouxe novos desafios à humanidade. Tais desafios se refletem no campo social e deflagram movimentos e lutas por um ambiente mais favorável à existência humana, como no campo educacional em que um número crescente de pesquisadores, buscam na atualização ou mesmo no questionamento dos paradigmas teóricos e conceituais que tratam desta temática (AZEVEDO; OLIVEIRA, 2014).

Face ao exposto, o presente estudo visa analisar os benefícios e malefícios das áreas consolidadas como Áreas de Preservação Permanente para garantir a proteção ambiental e conciliar as ações de preservação com o desenvolvimento sustentável.

\section{METODOLOGIA}

O trabalho foi realizado a partir de uma pesquisa bibliográfica que no entendimento, Oliveira (2004, p. 48):

A pesquisa bibliográfica é o estudo sistematizado desenvolvido com base em material publicado em livros, revistas, jornais, redes eletrônicas, isto é, material acessível ao publico em geral. Fornece instrumental analítico para qualquer outro tipo de pesquisa, mas também pode esgotar-se em si mesmo.

De acordo com Gil (1991 apud STAUDT, 2009), a principal vantagem da pesquisa bibliográfica reside no fato de permitir ao investigador a cobertura de uma gama de fenômenos muito mais ampla do que aquela que poderia pesquisar diretamente, tendo em vista a inviabilidade do pesquisador percorrer todo um território em busca de dados. Assim, a pesquisa bibliográfica é a análise dos dados que já estão prontos, registrados e que proporcionará aos pesquisadores ampliarem seus conhecimentos, fundamentando as respostas do problema analisado.

\section{RESULTADOS}

De acordo com a Lei $12.651 / 12$, art. $3^{\circ}$, IV , é considerada como área rural consolidada aquela que tenha ocupação antrópica consolidada até 22/07/2008 com edificações, benfeitorias e atividades agrossilvipastoris, admitida neste último caso a adoção do regime de pousio.

No entendimento de Schäffer et al. (2011, p.09):

Estas áreas possuem uma função ambiental relevante, uma vez que contribui para preservar os recursos hídricos, a paisagem, a estabilidade geológica, a biodiversidade, o fluxo gênico de fauna e flora, proteger o solo e assegurar o bem-estar das populações humanas.

A existência das áreas consolidadas deverá ser registrada no Cadastro Ambiental Rural da propriedade, para fins de monitoramento, exigindo em contrapartida dos detentores da terra a Colloquium Humanarum, vol. 14, n. Especial, Jul-Dez, 2017, p. 828-833. ISSN: 1809-8207. DOI: 10.5747/ch.2017.v14.nesp.001032 
adoção de técnicas de conservação do solo e água para atenuar os impactos ambientais causados pela presença das atividades humanas nas Áreas de Preservação Permanente (APP) (BORGES, 2011).

Como regra, o Código Florestal (Lei 12.651/2012) aprovado não admite a derrubada de mata nativa em áreas de inclinação entre $25^{\circ}$ e $45^{\circ}$ para uso do solo, sendo permitido apenas o manejo florestal sustentável. Porém, admite a manutenção, nas áreas rurais consolidadas, de atividades florestais, culturas de espécies lenhosas, perenes ou de ciclo longo, bem como da infraestrutura física a elas vinculada, desde que não se amplie a área ocupada até a data do decreto. A exceção à regra vale para áreas nas bordas dos tabuleiros ou chapadas, no topo de morros, com altura mínima de 100 metros e inclinação média maior que $25^{\circ}$, e nos locais de altitude superior a 1.800 metros.

\section{DISCUSSÃO}

O conceito estabelecido pela nova legislação é o de áreas rurais consolidadas, sendo esta definida como a área do imóvel rural com ocupação antrópica preexistente a 22 de julho de 2008, com edificações, benfeitorias ou atividades agrossilvipastoris, admitida, neste último caso, a adoção do regime de pousio, onde é autorizada, exclusivamente, a continuidade das atividades agrossilvipastoris, de ecoturismo e de turismo rural (considera-se, para tal, a área detida pelo imóvel rural em 22.07.2008) (CATAPLAN, 2013). A determinação da obrigatoriedade de recomposição de faixas de APPs de cursos d'água, nascentes, lagos e lagoas naturais e veredas, que variam conforme o número de módulos fiscais que compõe o imóvel rural (FISCHER, 2008).

Para os imóveis rurais, que possuam áreas consolidadas em Áreas de Preservação Permanente, no entorno de lagos e lagoas naturais, é admitida a manutenção de residências e da infraestrutura, associada às atividades agrossilvipastoris, de ecoturismo e de turismo rural, inclusive, o acesso a essas atividades, desde que não estejam em área que ofereça risco à vida ou à integridade física das pessoas.

Aos proprietários e possuidores dos imóveis rurais que, até 22 de julho de 2008, detinham até 4 módulos fiscais e desenvolviam atividades agrossilvipastoris nas áreas consolidadas em APPs, é garantido que a exigência de recomposição, somadas todas as APPs do imóvel, não ultrapassará: $10 \%$ da área total do imóvel, para imóveis rurais com área de até 2 módulos fiscais; e $20 \%$ da área total do imóvel, para imóveis rurais com área superior a 2 e de até 4 módulos fiscais (BRASIL, 2012). O Quadro 1 apresenta as características das APPs próximas aos rios:

QUADRO 1 - Área Consolidadas em APPs para rios.

\begin{tabular}{|c|c|c|}
\hline TAMANHO DA PROPRIEDADE & LARGURA DO RIO & LARGURA DA MATA CILIAR A SER RECUPERADA \\
\hline Até 1 módulo fiscal & Qualquer largura & $\begin{array}{l}5 \\
\text { (Art. 61-A, §1으, Lei 12.651/12) }\end{array}$ \\
\hline Superior a 1 até 2 módulos & Qualquer largura & 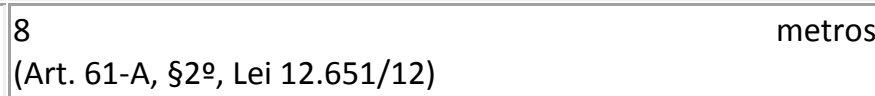 \\
\hline Superior a 2 até 4 módulos & Qualquer largura & $\begin{array}{l}15 \\
\text { (Art. 61-A, §3ㅇ, Lei 12.651/12) }\end{array}$ \\
\hline Superior a 4 até 10 módulos & Rios com até $10 \mathrm{~m}$ & $\begin{array}{l}20 \quad \text { metros } \\
\text { (Art. 61-A, §4ㅇiㄴ inciso II, Lei 12.651/12 e Dec. 7830/12, Art. } \\
19, \S 4 \text { o inciso I) }\end{array}$ \\
\hline Superior a 4 módulos & Rios > que $10 \mathrm{~m}$ & $\begin{array}{l}\text { Metade da largura do rio, sendo no mínimo } 30 \text { m e máximo } \\
100 \\
\text { (Art. } 61-\mathrm{A}, \S 40 \text { inciso II, Lei } 12.651 / 12 \text { e Dec. } 7830 / 12 \text {, Art. } \\
19, \S 40 \text { inciso II) }\end{array}$ \\
\hline
\end{tabular}

Fonte: BRASIL (2012). 
O Quadro 2 apresenta as características das APPs consolidadas em regiões de lagos e lagoas naturais:

QUADRO 2 - Área Consolidadas em APP's para lagos e lagoas naturais.

\begin{tabular}{|l|ll|}
\hline \multicolumn{1}{|c|}{ TAMANHO DA PROPRIEDADE } & \multicolumn{1}{|c|}{ ENTORNO DE LAGOS E LAGOAS NATURAIS A SEREM RECUPERADAS } \\
\hline Até 1 módulo fiscal & 5 metros & (Art. 61-A, §6ㅇ Inciso I) \\
\hline Superior a 1 até 2 módulos & 8 metros & (Art. 61-A, §6ㅇ Inciso II) \\
\hline Superior a 2 até 4 módulos & 15 metros & (Art. 61-A, §6ㅇ Inciso III) \\
\hline Superior a 4 módulos & 30 metros & (Art. 61-A, §6ㅇ Inciso IV) \\
\hline
\end{tabular}

Fonte: BRASIL (2012).

O Quadro 3 apresenta as características das APPs localizadas em veredas:

QUADRO 3 - Área Consolidadas em APPs para veredas.

\begin{tabular}{|c|c|}
\hline $\begin{array}{l}\text { TAMANHO DA } \\
\text { PROPRIEDADE }\end{array}$ & $\begin{array}{l}\text { FAIXA MARGINAL A SER RECUPERADA A PARTIR DO ESPAÇO BREJOSO E } \\
\text { ENCHARCADO }\end{array}$ \\
\hline Até 4 módulos & (Art. 61-A, §70 Inciso I) \\
\hline Superior a 4 módulos & (Art. 61-A, §7ㅇInciso II) \\
\hline
\end{tabular}

Fonte: BRASIL (2012).

De acordo com a legislação vigente (BRASIL, 2012), nas áreas rurais consolidadas nas APPs de encostas, de bordas dos tabuleiros ou chapadas, no topo de morros, montes, montanhas e serras e de altitude superior a $1.800 \mathrm{~m}$, será admitida a manutenção de atividades florestais, culturas de espécies lenhosas, perenes ou de ciclo longo, bem como da infraestrutura física, associada ao desenvolvimento de atividades agrossilvipastoris, vedada a conversão de novas áreas para uso alternativo do solo.

As situações entendidas como consolidadas em APP, conforme definido, deverão ser informadas no CAR para fins de monitoramento, sendo exigida, nesses casos, a adoção de técnicas de conservação do solo e da água que visem à mitigação dos eventuais impactos. Estabelece, ainda, que a manutenção das atividades previstas observará critérios técnicos de conservação do solo e da água indicados no programa de regularização ambiental incumbindo-se aos Estados e ao Distrito Federal o detalhamento destes. Mantém a vedação da conversão de novas áreas para uso alternativo do solo nestes locais (BRASIL, 2012).

Para áreas urbanas o Parecer Técnico n. 204/2010-4a-CCR do Ministério Público Federal determina que:

O conceito de área urbana consolidada (art. 2º) tornará mais liberal a ocupação e o uso alternativo de APP, reduzindo a proteção. Os critérios de reconhecimento da área urbana consolidada, que não incluirão a exigência de que a área já seja habitada, permitem a criação de áreas urbanas "consolidadas" a qualquer tempo, independentemente da existência prévia da ocupação, possibilitando a abertura de novos assentamentos urbanos em APP.

Desta perspectiva compreende-se que o conceito de propriedade privada se torna relativizado, uma vez que os proprietários de loteamentos urbanos, para construir edificações, deverão respeitar as áreas de preservação permanente, dentro das áreas urbanas consolidadas, 
visando o cumprimento do direito fundamental expresso na Constituição, que é o respeito ao meio ambiente ecologicamente equilibrado (REIS, 2010).

\section{CONCLUSÃO}

Com a realização deste estudo foi possível analisar a importância das áreas consolidadas de preservação permanente e seus benefícios para a proteção ambiental. O que se pode analisar de acordo com a literatura consultada, há um antagonismo entre ruralistas e ambientalistas, em relação à utilização de áreas de preservação permanente sendo que, ao permitir que a vegetação das APP'S sejam destruídas, a nova lei em vigor, priorizando o desenvolvimento econômico em detrimento do desenvolvimento e da manutenção de recursos naturais.

O que se percebe é que, de certo modo, o Novo Código Florestal protege os autores dos desmatamentos, que são prejudiciais ao meio ambiente, e permitindo que, atividades agressivas à natureza, continuem sendo desenvolvidas em Áreas de Preservação Ambiental.

As definições e limites adotados na legislação brasileira em relação às áreas consolidadas se apresentam como um instrumento legal para a proteção ambiental dos recursos naturais existentes em nosso país. Por meio da legislação vigente sobre áreas consolidadas se verifica o disciplinamento da ação antrópica sobre o meio ambiente, possibilitando a manutenção de ecossistemas aquáticos e terrestres.

Desta forma, por meio deste estudo, pode-se verificar que, a legislação sobre as APPs nas áreas urbanas consolidadas, surgiu como resultado do interesse e preocupação em gerar mecanismos para a proteção ambiental.

Um dos principais benefícios das áreas consolidadas é a proteção legal utilizando por mecanismos práticos estabelecidos pelo Conselho Nacional do meio Ambiente (CONAMA). Outro benefício é que a delimitação de áreas consolidadas é meio de se atingir o desenvolvimento sustentável tão almejado na atualidade, propiciando a qualidade ambiental e o bem-estar da população. Dentre os benefícios das áreas consolidadas se apresentam: controle hidrológico; manutenção de vegetação que evita erosão, permanência de fauna e flora nativa, maior estabilidade do solo em áreas de cultivo. No entanto ainda são necessárias ações para corrigir erros e tornar eficiente a aplicação da legislação.

\section{REFERÊNCIAS BIBLIOGRÁFICAS}

AZEVEDO, Ruy Emmanuel Silva de; OLIVEIRA, Vládia Pinto Vidal de. Reflexos do novo Código Florestal nas Áreas de Preservação Permanente - APPs - urbanas. Desenvolvimento e Meio Ambiente, v. 29, p. 71-91, abr. 2014.

BORGES, Luís Antônio Coimbra et al. Áreas de preservação permanente na legislação ambiental brasileira. Cienc. Rural, Santa Maria, v. 41, n. 7, p. 1202-1210, jul. 2011.

BRASIL. Presidência da República. Casa Civil. Subchefia para Assuntos Jurídicos. Lei no 12.651, de 25 de maio de 2012. Dispõe sobre a proteção da vegetação nativa; altera as Leis nos 6.938, de 31 de agosto de 1981, 9.393, de 19 de dezembro de 1996, e 11.428, de 22 de dezembro de 2006; revoga as Leis nos 4.771, de 15 de setembro de 1965, e 7.754, de 14 de abril de 1989, e a Medida Provisória no 2.166-67, de 24 de agosto de 2001; e dá outras providências. Brasília, 2012. Disponível em: <http://www.planalto.gov.br/ccivil_03/_ato2011-2014/2012/lei/l12651.htm>. Acesso em: 07 ago. 2017.

CATAPAN, Anderson et al. O novo código florestal e sua abrangência nas áreas urbanas. Revista Meio Ambiente e Sustentabilidade. Uninter, Curitiba, v. 4 n.2, jul/dez 2013. Disponível em: 
<https://www.uninter.com/revistameioambiente/index.php/meioAmbiente/article/viewFile/221/ 117>. Acesso em: 07 ago. 2017.

FISCHER, Ana Claudia, et al. Critérios para Delimitar Áreas de Preservação Permanente em Rios de Planície de Inundação. Revista Brasileira de Recursos Hídricos, v. 13, n. 3, p. 83-91, jul./set. 2008. Disponível em: <https://www.abrh.org.br/SGCv3/index.php?PUB=1\&ID=14\&SUMARIO=169>. Acesso em: 07 ago. 2017.

MINISTÉRIO PÚBLICO FEDERAL. Parecer Técnico no 204/2010. 4ạ Câmara de Coordenação e Revisão. Meio Ambiente e Patrimônio Cultural. Disponível em: < http://www.mpf.mp.br/atuacaotematica/ccr4/dados-da-atuacao/documentos/trabalhos-cientificos/pt204-

10_substitutivo_codflorestal.pdf>. Acesso em: 3 maio 2017.

REIS, Patrícia Lima de S. Oliveira. Áreas de preservação permanente em área consolidada urbanizada. Jus.Com.Br. Artigos. 2014. Disponível em: < https://jus.com.br/artigos/33869/areasde-preservacao-permanente-em-area-consolidada-urbanizada>. Acesso em: 3 jun. 2017.

SCHÄFFER, Wigold Bertoldo et al. Áreas de Preservação Permanente e Unidades de Conservação \& Áreas de Risco. O que uma coisa tem a ver com a outra? Relatório de Inspeção da área atingida pela tragédia das chuvas na Região Serrana do Rio de Janeiro. Brasília: MMA, 2011. Disponível em: <http://www.mma.gov.br/estruturas/202/_publicacao/202_publicacao01082011112029.pdf>. Acesso em: 07 ago. 2017.

STAUDT, Vanessa B. A influência do líder na motivação dos colaboradores: estudo de caso na empresa D. Dapper Transportes Ltda. Centro universitário FEEVALE - Novo Hamburgo-RS, 2009. 